\title{
Cansancio emocional relacionado con el Estrés percibido durante el aprendizaje en modalidad E- learning en estudiantes de bachillerato
}

\author{
Emotional Tiredness related to Perceived Stress during E-learning in high school \\ students \\ Xanat Alvarez Oviedo ${ }^{a}$, Gabriel Eduardo Lara-Abab ${ }^{b}$, Fernando Ignacio Sánchez-Flores $^{c}$
}

\begin{abstract}
:
The objective of the present study was to determine the prevalence of Emotional Tiredness (CE) before Stress in high school students. The study corresponded to a quantitative, descriptive and cross-sectional investigation. The total number of students $(\mathrm{n}=$ 100) from five groups from 1st to 6th semester belonging to Preparatory Schools of the Autonomous University of the State of Hidalgo were counted, obtaining a response level of $63 \%(n=63)$. The Emotional Tiredness Scale $(E C E)$ of Ramos, Magas \& Morán (2005) and the Perceived Stress Scale (SPS) Cohen, Kamarak, and Mermelstein (1983) were used and validated. As main findings, a significant high correlation was detected between perceived stress in recent months with emotional exhaustion.
\end{abstract}

Keywords:

Emotional tiredness, stress, E-Learning.

Resumen:

El objetivo del presente estudio fue determinar la prevalencia del Cansancio Emocional (CE) ante el Estrés en alumnos de bachillerato . El estudio correspondió a una investigación de tipo cuantitativo, descriptivo y transversal. Se censó al total de alumnos $(n=100)$ de cinco grupos de 1er a 6to semestre pertenencientes a Escuelas Preparatorias de la Universidad Autónoma del Estado de Hidalgo, obteniendo un nivel de respuesta del 63\% $(\mathrm{n}=63)$. Se utilizaron y validaron la Escala de Cansancio Emocional (ECE) de Ramos, Magas \& Morán (2005) y La Escala de Estrés Percibido (SPS) Cohen, Kamarak, y Mermelstein (1983). Como principales hallazgos se detectó una alta correlación significativa entre el estrés percibido en los ultimos meses con el cansancio emocional.

Palabras Clave:

Cansancio emocional, estrés, e-learning.

\section{Introducción}

En el último año y medio a partir del surgimiento del virus SAR-COV-2, ha provocado una crisis sin precedentes alrededor de todo el mundo y en todos los ámbitos posibles, principalmente en el educativo. Esta emergencia ha dado lugar al cierre generalizado de todas las actividades presenciales y de todas las instituciones educativas en más de 190 países, con el objetivo de evitar la propagación del virus y mitigar el efecto de su impacto. De acuerdo con la CEPAL (2020), gran parte de las medidas que los países han adoptado, derivado de la crisis sanitaria causada por la COVID-19, se relacionan con la suspensión de las clases presenciales en todos los niveles, lo que ha dado origen a la modalidad E-Learning.

Existe una gran cantidad de autores que señalan que el e-learning nutre la experiencia y la calidad educativa, la hace más rápida, ayuda a reducir los costos tanto a las instituciones educativas como a las familias, sin embargo, se pueden identificar efectos negativos a nivel psicológico. Según Lovón \& Cisneros (2020), este hecho unido con una flexibilidad necesariamente impuesta tuvo

Autor de Correspondencia, Universidad Autónoma del Estado de Hidalgo, https://orcid.org/0000-0001-8048-7063, Email: xanat_alvarez@uaeh.edu.mx

${ }^{\mathrm{b}}$ Universidad Autónoma del Estado de Hidalgo, https://orcid.org/0000-0003-2748-5573, Email: gabriel_lara9718@uaeh.edu.mx

c Universidad Autónoma del Estado de Hidalgo, https://orcid.org/0000-0002-9051-4907, fernando sanchez11119@uaeh.edu.mx 
como consecuencia un aumento excesivo en los niveles de estrés en el alumno de bachillerato, misma que, a su vez, predisponen a los estudiantes a sufrir cansancio emocional.

Una de las definiciones más aceptadas actualmente es la elaborada por Maslach y Jackson (1981), que hace referencia a tres dimensiones: Cansancio Emocional, Despersonalización y baja Realización Personal. El Cansancio Emocional implica que la fuerza o capital emocional se han consumido y el sujeto siente que no es capaz de dar más de sí mismo a los demás, desde un nivel personal y psicológico. El alumno se siente exhausto tanto física como psíquicamente, con sensaciones de impotencia y desesperanza. Algunos de los alumnos en este nivel se encuentran enfrentando el Estrés producido por exámenes, las preocupaciones sobre los trabajos escolares, competitividad ante el grupo, problemas con los asesores, las calificaciones, etc, que hacen realmente difícil su vida. Otros, sin embargo, enfrentan estos mismos problemas demostrando resistencia y capacidad para afrontarlos exitosamente. Esto se debe al desarrollo de habilidades para enfrentar el Estrés. Hace pocos años, Ramos, Mangas \& Morán (2005) comenzaron a hablar de "estudiantes quemados" refiriéndose al estrés académico causado por los estudios y exámenes en la universidad, bachillerato y posgrado, por lo que diseñaron la ECE Escala de Cansancio Emocional, la cual pudiera medir el constructo de cansancio emocional en estudiantes, tomando en cuenta aspectos como: La personalidad, autoconcepto, autoestima, salud psicológica y satisfacción con los estudios.

Por esta razón el propósito central del presente estudio es conocer la relación existente entre el estrés y cansancio emocional en estudiantes de bachillerato de la UAEH. Por lo anterior los resultados de la presente investigación podrán aportar nuevas expectativas orientadas a una mejora en las estrategias educativas de modalidad e-learning así mismo, conocer la correlación de las variables estrés y cansancio emocional para investigaciones futuras.

\section{Método.}

\section{Tipo de investigación.}

El estudio correspondió a una investigación de tipo cuantitativo, descriptivo y transversal, ya que se buscó medir y detallar el Cansancio emocional y Estrés en un único momento.

\section{Población}

Se censó al total de alumnos $(n=100)$ de 5 grupos de diferentes niveles (1ero a 6to semestre) de las escuelas preparatorias pertenecientes a la UAEH obteniendo un nivel de respuesta del 63\% ( $n=63), 42$ mujeres y 21 hombre, tomando a consideración que los participantes se encontraran cursando sus estudios en modalidad elearning durante los últimos 12 meses.

\section{Instrumentos.}

Escala de Cansancio Emocional (ECE). Este instrumento fue desarrollado por Ramos, Mangas \& Morán (2005) para medir el cansancio emocional derivado del estrés generado por la carga académica en los estudiantes de nivel bachillerato, universidad y posgrado resultando el análisis de 5 dimensiones: factores de personalidad, autoconcepto, autoestima, salud psicológica y satisfacción con los estudios. La ECE es una escala unidimensional de 10 ítems, con un nivel aceptable de consistencia interna (un coeficiente alfa de . 83) y una satisfactoria homogeneidad de ítems (correlación media entre ítems $=$. 33). Los ítems se puntúan de 1 a 5 , considerando los 12 últimos meses de vida estudiantil, según ocurra lo que la frase dice: 1 raras veces, 2 pocas veces, 3 algunas veces, 4 con frecuencia, 5 siempre. Los ítems están inspirados en los de la escala de cansancio emocional del Maslach Burnout Inventory (Maslach. y Jackson, 1997), como también en ítems incluidos en el concepto de burnout de Freudenberger (Morán, 2003). A esta base se añaden ítems especialmente diseñados para evaluar el cansancio o desgaste emocional de los estudiantes, cansancio derivado del nivel de exigencia y de esfuerzo por superar los estudios. La puntuación obtenida en la ECE oscila entre los 10 y los 50 puntos.

La Escala de Estrés Percibido (SPS) es la versión en español de la escala de estrés percibido de Cohen, Kamarak, y Mermelstein (1983) fue traducida en el 2006 por Eduardo Remor. Dicha escala está formada por 14 ítems. En cuanto a la confiabilidad y validez de constructo de la Escala de Estrés Percibido aplicada en estudiantes de Baja California, se presentó un adecuado nivel de confiabilidad ( $\alpha=.86)$, y el modelo de medida presentó un ajuste adecuado: $\mathrm{GFI}=.91$, RMSEA=.056, $\mathrm{NFI}=.97, \mathrm{CFI}=.98, \mathrm{IFI}=.98$. Brito-Ortiz \& Nava-Gómez (2019).

En el factor a favor del control, las puntuaciones de los ítems 4, 5, 6, 7, 9, 10, y 13 se invierten para valorar el estrés. Los ítems se evalúan mediante una escala de frecuencia con formato de gradientes tipo likert de 5 grados, que va de 1 (Nunca) a 5 (Muy frecuentemente: 
todos los días), correspondiendo a un caso igual a 3 (De vez en cuando) en la puntuación total.

\section{Análisis de los datos.}

La información se analizó siguiendo la estructura de cada instrumento. En el caso de la Escala de Cansancio emocional se optó por realizar una sumatoria de las puntuaciones obtenidas de cada participante y de esta forma obtener una sumatoria total. Para realizar el análisis de la Escala de Estrés Percibido, fue necesario calcular dos sumatorias: la primera, correspondiente a los items $1,2,3,8,11,12,14$, la segunda que toma en cuenta los items 4, 5, 6, 7, 9, 10, y 13 los cuales se invierten para medir los factores favorables relacionados con el afrontamiento de estrés.

Se realizó el análisis con el Paquete Estadístico para las Ciencias Sociales (SPSS) en su versión 21, llevando a cabo una correlación bivariado entre la sumatoria de la Escala de Cansancio Emocional y la sumatorias totales de la Escala de Estrés Percibido.

\section{Resultados.}

Se calculó el nivel de fiabilidad de la ECE aplicada a estudiantes de bachillerato, presentando un nivel aceptable de consistencia interna $(\mathrm{a}=.89)$. En cuanto a la validez de la SPS aplicada en la misma población, se observa un adecuado nivel de confiabilidad $(a=.90)$.

En la tabla 1 se muestra los datos de la correlación bivariado. Se puede observar en los resultados, que existe una alta correlación positiva entre la variable Estrés percibido y el Cansancio emocional lo cual se puede interpretar de la siguiente manera: a mayor nivel de estrés mayor prevalencia del cansancio emocional. El $49.2 \%$ de los estudiantes a nivel bachillerato de la UAEH han presentado un nivel medio de estrés en el último mes, lo que significa un aumento del cansancio emocional, ya que de acuerdo con los datos obtenidos en la Tabla 2 existe una alta correlación en el Item 3 de la SPS con el Item 6 de la ECE. En la Tabla 2 se muestran las correlaciones de los items que presentaron índices significativos de Estrés y Cansancio emocional.

Se obtuvieron diferencias estadísticamente significativas entre los semestres cursados, ya que se observan mayores niveles de Estrés en alumnos que se encuentran en primer semestre comparados con los niveles de afrontamiento de los alumnos de 5 to y 6 to semestre lo cual podría explicarse por la diferencia del tiempo de adaptación a la modalidad e-leraning.

\section{Conclusiones.}

En correspondencia con el propósito de la presente investigación, podemos mencionar que existe una alta correlación entre el Estrés percibido y el Cansancio emocional en estudiantes de bachillerato de la UAEH.

De acuerdo con la literatura de Lovón \& Cisneros (2020), los resultados obtenidos coinciden, dado que la predisposición forzada a la adaptación de la modalidad e-learning genera implicaciones psicológicas como el cansancio emocional.

Las actividades académicas requieren de habilidades y conocimientos teóricos, además, herramientas psicosociales que permitan la adaptación con la instancia educativa y la satisfacción por el estudio.

Esta investigación contribuye a futuros estudios relacionados con el diseño de intervenciones que favorezcan el desarrollo de habilidades de afrontamiento al estrés en crisis circunstanciales, así como la realización de algunas adecuaciones en las actividades académicas que reduzcan los efectos del cansancio emocional. Se considera también que el presente trabajo sea una pauta para indagar las causas multifactoriales del cansancio emocional en estudiantes, ya que los estudios realizados en México son escasos, y contrastando los resultados de las investigaciones de la variable en otros países, podría ser un gran paso para la mejora del rendimiento académico.

\section{Referencias.}

Ramos, F., Manga, D., \& Morán, C. (2005). Escala de cansancio emocional (ECE) para estudiantes universitarios: Propiedades psicométricas y asociación. Interpsiquis. Recuperado de: http:// www.psiquiatria.com/articulos/ estres/20478/.

Comisión Económica para America Latina y el Caribe. (2020). Universalizar el acceso a las tecnologías digitales para enfrentar los efectos del COVID-19.

Lovón, M., Cisneros., S.(2020). Repercusiones de las clases virtuales en los estudiantes universitarios en el contexto de la cuarentena por COVID19. Perú.

Maslach, C. \& Jackson, S. (1981). The measurement of experienced burnout. Journal of Occupational Behaviour, 2, 99-113

Maslach, C. y Jackson, S. E. (1997). MBI. Inventario "Burnout" de Maslach. Madrid: TEA Ediciones.

Morán, C. (2003). Relación entre variables de personalidad y estrategias de afrontamiento del estrés laboral. Tesis doctoral. León: Universidad de León. 
Cohen, S., Kamarak, T., \& Mermelstein, R. (1983). A global measure of perceived stress. Journal of Health and Social Behaviour.

Brito-Ortíz, J.F, Nava-Gómez, M.E. y Juárez-García, A. (2019). Escala de estrés percibido en estudiantes de odontología, enfermería y psicología: validez de constructo. Revista ConCiencia. 